\title{
A identidade das formas linguísticas sob o ponto de vista das operações predicativas e enunciativas
}

The identity of linguistic forms from predicative and enunciative point of view

1 Doutor em Linguística e Língua Portuguesa pela UNESP/Araraquara, professor adjunto da Universidade do Estado de Mato Grosso, coordenador do Programa de Poss-Graduaçáo em Linguistica de (CNPq). (iD) http://orcid.org/0000-0002-7033-304 E-mail: adallapria@gmail.com

Doutor em Linguistica e Língua Portuguesa pela UNESP/Araraquara, docente do Programa de PósGraduação em Linguistica da UNEMAT/Campus de Caceres, bolsista PNPD/CAPES/UNEMAT (iD) http://orcid. org/0000-0002-2136-734 E-mail: marcoscumpri@yahoo.com.br Doutor em Linguística pela UNICAMP, professor adjunto da Universidade do Estado de Mato Grosso, docente do Programa de Pós-Graduaçấ em Linguística da UNEMAT/Campus de Cáceres, coordenou a organizaçáa dos dois volumes das cidades brasileiras: um estudo semânticoenunciativo do Mato Grosso, pela Editora Pontes. (1)_https://orcid. org/0000-0001-6423-5640

E-mail: taisirkarim@hotmail.com
Albano Dalla Pria ${ }^{1}$ Marcos Luiz Cumpri ${ }^{2}$ Taisir Mahmudo Karim ${ }^{3}$

Universidade do Estado de Mato Grosso, Cáceres, MT, Brasil.

\section{RESUMO}

Neste trabalho, defendemos que não se pode escapar da variação radical (REZENDE, 2000; 2008; 2014) que fundamenta a identidade das formas linguísticas. Com o objetivo de apreender o funcionamento dinâmico das unidades na prática de produção e reconhecimento de enunciados, simulamos uma situação enunciativa entre sujeitos e, manuseando as unidades morfolexicais um, o e cachorro dos enunciados do diálogo de partida, segundo os pressupostos da Teoria das Operações Predicativas e Enunciativas, formalizamos o funcionamento dessas formas no processo de determinação nominal. Para tanto, explicitamos invariantes de base e reafirmamos a sua importância para a sustentação quer dos valores construídos em língua quer da apropriação desses valores peelos sujeitos. Com efeito, esperamos ter contribuído para a compreensão de que, de um ponto de vista enunciativo, a identidade das formas linguísticas é o construto de uma prática (trabalho), que articula uma invariante de base com a diversidade linguística e experiencial.

Palavras-chave: Nominal. Determinação. Variação. Invariante.

\section{ABSTRACT}

In this paper, the hypothesis that we cannot abstract from the radical variation (REZENDE, 2000, 2008, 2014) that underlies the identity of linguistic forms is widely defended. With the objective of apprehending the dynamic functioning of the units in the practice of production and recognition of utterances, an enunciative situation between subjects was simulated and, by dealing with the morpho-lexical units um, $o$ and cachorro from the utterances of the dialogue, according to the assumptions of the Theory of Predictive and Enunciative Operations, the functioning of these forms in the process of nominal determination was formalized. For this purpose, invariants were made explicit and their importance was reaffirmed for supporting both the values constructed in language and the appropriation of these values by the subjects. In fact, we hope to have contributed to the understanding that, from an enunciative point of view, the identity of the linguistic forms is the construct of a practice (work) that articulates a basic invariant with linguistic and experiential diversity.

Keywords: Nominal. Determination. Variation. Invariant. 


\section{Introdução}

quilo que conhecemos como sendo a estrutura da língua (la langue) diz muito pouco sobre a trajetória de estabilização das formas linguísticas, porque apreende apenas os momentos de estabilidade das formas. Ademais, esse tipo de apreensão tende a produzir uma falsa imagem de estabilidade constante ou de uma invariante estática imanente às formas. Ainda desse ponto de vista, os arranjos léxico-gramaticais pouco ou nada contribuem para a construção da significação. A estabilidade intersubjetiva é tão presumida quanto a estabilidade das formas que se pretende descrever.

Não é sem razão o conflito entre as categorias da morfossintaxe e o perpétuo movimento de reorganização das formas que se observa ao nível do discurso. Já do ponto de vista da atividade enunciativa, tal como a entendemos, a estabilização das formas constitutivas do enunciado é um evento em processo, que se orienta por um horizonte de estabilidade.

A título de exemplo, tomemos a unidade compra ${ }^{1}$. Tal como é descrita por gramáticas e dicionários, sob o argumento de ter sido derivada do verbo comprar, seu valor primeiro será processual. Esse seria o caso para a compra de Pedro. Mas, observe-se, não se explicita a asserção sob a qual se chegou a essa assunção. Confirmada a previsão de que Pedro será afetado pela experiência (a compra), tanto basta, desse ponto de vista, para se afirmar que o verbo em questão indica um processo. Para casos "residuais", fica previsto um valor "secundário" designativo para a unidade. Tal é o caso para a compra do livro, embora também não se explicite a asserção sob a qual se chegou a tal conclusão. Do ponto de vista descritivo, busca-se investigar os mecanismos que sustentam as formas e os valores das unidades das línguas, na égide das gramáticas e dos dicionários (compra = "ação de comprar";

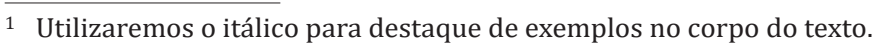

"coisa comprada” (MICHAELIS, 2015)). Que tratamento é dado àqueles casos em que a asserção força um valor imprevisível? Qual o tratamento das subversões aos valores previsíveis da gramática?

A esse respeito, considerem-se, por exemplo: (a) A compra de Pedro nunca deu tão certo, ele ficou feliz como nunca e (b) A compra do livro anda trabalhosa demais, talvez nem aconteça. Em (a) construímos um valor designativo para compra e, em (b), um valor processual. Observe-se, no entanto, que o valor designativo de compra, em (a), e o processual, em (b), somente pode ser apreendido se observada não apenas a unidade compra, mas a sua integração com as marcas de asserção do enunciado. Através do conceito de operação (CULIOLI, 1990; 1999; 2002), mais do que reconhecer a "capacidade de integração" (BENVENISTE, 2005, p. 136) das unidades, avançaremos, neste artigo, com os processos pelos quais a integração se constrói na constituição do enunciado.

São marcas aspecto-modais (nunca deu; tão certo; feliz) que nos permitem atribuir o valor designativo a compra, em (a), assim como também são marcas dessa natureza (anda trabalhosa; talvez aconteça) que nos levaram a atribuir um valor processual à unidade, em (b). E, como não temos estados resultantes (livro comprado), em (b), temos de assumir que "não são as unidades com valor determinados que se relacionam, mas a relação das unidades que gera os valores" (REZENDE, 2011, p. 1622).

Embora não seja nosso intuito construir questionamentos a esse respeito, não podemos deixar de lembrar que tratar como autônomas as unidades e suas relações é, no mínimo, questionável. O resultado de tal procedimento tende a produzir uma imagem artificial ou superficial dos fenômenos, como acima se exemplificou.

Na esteira dos trabalhos de Rezende (2008; 2014), defendemos, neste artigo, que não se pode escapar da variação radical que fundamenta a identidade das formas linguísticas. Não se pode escapar porque, quer no 
plano experiencial ou cognitivo, quer no plano linguístico ou empírico, "só há variação” (REZENDE, 2008, p. 97), isto é, “[...] uma variação radical de experiência (variação espaço-temporal dos indivíduos) e de expressões linguísticas correspondentes" (REZENDE, 2014, p. 81).

Assim, recolocamos a problemática da variação e, com ela, o papel das formas linguísticas no processo de construção da significação. Para tanto, recorremos a raciocínios de uma ordem diferente daquela que sustenta a autonomia das formas. Com efeito, buscamos apreender o funcionamento dinâmico das unidades na prática de produção e reconhecimento de enunciados.

Aqui na introdução já explicitamos a ambivalência do nome compra e como a asserção do contexto encaixante (modalidade e aspecto) contribui para a sua determinação. Na quarta seção, também explicitaremos a ambivalência do nome cachorro, que não está catalogada em gramáticas e dicionários, enquanto nome de propriedade (ser cachorro) e enquanto nome de indivíduos (um cachorro, outro cachorro, e assim por diante) e como os artigos (definidos e indefinidos), enquanto marcadores de operações, contribuem para a sua determinação.

Antes disso, reafirmaremos, na segunda e terceira seções, a importância, para uma teoria enunciativa, qualquer que seja ela, de se lidar de algum modo com os cenários subjacentes à diversidade do empírico. No nosso caso, em particular, é a Teoria das Operações Predicativas e Enunciativas ${ }^{2}$ (doravante TOPE) que nos ajuda a lidar com essas invariantes de base geradoras de enunciados. A teoria nos fornece dois mecanismos organizadores da derivação de enunciados: a "parafrasagem" e a atividade de "desambiguização". Através deles buscamos controlar a coerência

Três tomos intitulados Pour une linguistique de l'énonciation, de Antoine Culioli, publicados pela
editora francesa Ophrys, reúnem um conjunto de trabalhos que são basais para nossas discussões. Dois desses tomos estão referenciados neste artigo. parafrástica dentro de uma latência de significações que tendem a proliferar a cada gesto de linguagem.

Na segunda seção, não tanto com o intuito de análise, mas de exemplificação dos pressupostos da TOPE, apropriamo-nos do verbo quebrar e trabalhamos a sua contextualização articulada com uma invariante de base. Na terceira seção, tratamos de como lidamos com a variação tendo assumido a tese da indeterminação da linguagem por fundamento. Ressalte-se que, no conjunto dos dois nomes, compra e cachorro, e do verbo quebrar, queremos mostrar que é um conjunto de operações da linguagem que está sustentando a variação ou os "desarranjos" (outros arranjos?) na relação entre a forma e o conteúdo em língua.

Em tempo de já passarmos à segunda seção, conforme se poderá observar de nossas posições, defendemos que a gênese de toda a variação é experiencial e subjetiva, e não formal ou processual, no sentido mais usual desses termos.

\section{A investigação que vai do formal ao empírico}

O que justificaria a aplicação de um método (ou raciocínio) homogeneizante a fenômenos variáveis? Seria para se proteger da diversidade de raciocínios subjacentes à variação? A pergunta pode causar algum estranhamento. Afinal, de um lado, por que um ponto de vista que usualmente não justifica o seu método, agora o teria de justificar? De outro lado, por que teríamos nós de justificar nossas opções? Nesta seção, buscaremos responder ao imperativo "Explicite o método!".

A necessidade de explicitar o método seria em razão de uma exigência de previsibilidade? Ou, ainda, de garantias de resultados favoráveis ou úteis? Sob quais objetivos estariam assentadas essas exigências? Seriam relações de poder tentando determinar trajetórias? Tecendo críticas às exigências 
da explicitação do método, Gadotti (1995), retomando algumas expressões de Bachelard (1972), afirma que "a história de um método (= caminho) só pode ser "contada ao finalizar a pesquisa”. A direção tomada inicialmente é sempre provisória” (GADOTTI, 1995, p. 14).

A metodologia da TOPE pode parecer estranha a uma linguística cujo objetivo não seja "compreender a atividade de linguagem através da diversidade das línguas naturais (e através da diversidade de textos, orais e escritos)" (CULIOLI, 1990, p.14). No nosso caso, que optamos por apreender a linguagem como um objeto clivado entre o formal e o empírico, a metodologia implica a articulação desses dois planos.

No plano formal, está a linguagem e, no empírico, a diversidade experiencial e linguística. Como prever os resultados dessa articulação? Como prever os observáveis desse ponto de vista teórico? Se, por um lado, não há como prever os modos pelos quais cada enunciado construirá sua trajetória de determinação, por outro lado, não ignoramos a possibilidade de se fazer alguma previsão, a saber: a de que todo enunciado constrói a sua trajetória. Não dispomos de meios para fornecer a previsão formal do perfil dessa trajetória ou, em última instância, prever o seu resultado. (Essa talvez possa ser tomada como uma previsão, por que não?) Não podemos ignorar que, sob o invólucro da "previsibilidade", ficam suprimidos da observação os processos de adaptação do material verbal que, em face da imprevisibilidade do empírico, (re)organiza a sua memória experiencial.

A linguagem é o mecanismo (formal) que está na origem de qualquer sequência interpretável, mas não só. Como tal, esse mecanismo desconhece as adequações do empírico, como nomes referindo indivíduos, verbos referindo processos, adjetivos referindo propriedades de indivíduos, e assim por diante. A linguagem é imprevisível. Assim como é indeterminada, opaca ou não transparente para qualquer configuração da experiência que se considere. A linguagem enquanto mecanismo operatório na produção e no reconhecimento de sequências interpretáveis é sempre colocada em funcionamento por um sujeito imerso no empírico. Trata-se de "um sujeito que fala e que está inserido em um meio ambiente, e que, quando fala, referese a universos extralinguísticos que lhe são externo e interno (realidade física e cultural) e interno e externo (realidade psíquica)" (REZENDE, 2000, p. 124-125).

O empírico, ao contrário, arrasta a historicidade da sua constituição. Está organizado em razão de trajetórias particulares dos sujeitos no meio psicofísico e cultural, cujas marcas podem ser apreendidas da configuração do enunciado. De um certo ponto de vista, convencionou-se tratar como "previsível" a coincidência, não por acaso, de certos resultados adequados já mencionados no parágrafo anterior. A questão é que, para referir, o sujeito tem de situar representações ${ }^{3}$ (um objeto simbólico) em relação ao meio ${ }^{4}$, em um movimento de construção do formalizável. Esse processo que implica a construção de representações significativas (representação), a localização dessas representações no empírico (referenciação) e o ajustamento das representações em relação à alteridade (regulação) (CULIOLI, 1990, p. 177) não tem nada de previsível. Recorde-se do nome compra e da sua ambiguidade constitutiva. Como lidar, então, com o imprevisível?

Para tanto, colocamos teoricamente a existência de um momento anterior, quando o léxico e a gramática ainda não estão recortados e adequados. Agora, quando as unidades da superfície da língua já se encontram recortadas (a fonologia e a morfossintaxe), de um ponto de vista acústico ou gráfico, o que observamos é a coordenação de unidades que

${ }^{3}$ Trata-se de um conceito metalinguístico que remete a um evento em processo de construção, no caso, a construção de significação articulada com "unidades morfolexicais apreendidas através da variação de cou sentido" (FRANCKE, 2002, p. 3, tom "uña ão nor seu sentido" (FRANCKEL, 2002, p. 3, tradução nossa). Não se trata da representação de propriedades 4 Apesar de soar redundante, ressalte-se: o meio (empírico) é constitutivo do sujeito do empírico. Apesar de soar redundante, ressalte-se: o meio (empírico) é constitutivo do sujeito (da sua memória experiencial), assim como o sujeito (através de mecanismos da linguagem) é constitutivo do meio
(porque dele se apropria para se equilibrar). 
se encontram dispostas em uma sequência, tal como em Pedro quebrou o brinquedo. Na fala, produzimos uma unidade após a outra. E a escrita, de algum modo, busca reproduzir essa disposição.

Do ponto de vista da produção e do reconhecimento de sequências (acústicas ou escritas) interpretáveis, vamos além das aparências, isto é, além da percepção das unidades em uma sucessão linear. Por hipótese, as marcas ou os arranjos léxico-gramaticais da superfície são o caminho de acesso a um plano mais profundo, que é o da atividade epilinguística, fundamentada pelo diálogo enquanto movimento que vai do formal (todo mecanismo de derivação de representações linguísticas e cognitivas) ao empírico (toda a configuração disponível à simbolização), e vice-versa.

Os processos pelos quais uma sequência é apreendida por um dado sujeito é tão variável quanto imprevisível e ilustra bem o diálogo entre o formal e o empírico. Consideremos, a seguir, pelo menos três das estabilizações possíveis para Pedro quebrou o brinquedo:

Cenário 1: O Pedro [que tem a propriedade de quebrar brinquedo, dentre outras coisas] quebrou o brinquedo;

Cenário 2: o Pedro quebrou [dentre outras coisas que se poderiam quebrar, logo] o brinquedo;

Cenário 3: [se era para alguém quebrar alguma coisa qualquer] O Pedro quebrou o brinquedo.

As paráfrases dão conta da conformidade ou adequação dos cenários anteriores. Nesse caso, as propriedades das noções semânticas em relação /Pedro/, /quebrar/ e /brinquedo/ ${ }^{5}$ estão fundidas com o contexto. Nos Cenários 1, 2 e 3, separamos, artificialmente, o contexto [entre colchetes] e a construção fora dos colchetes. Tendo alcançado um ponto desejável de

${ }^{5}$ Neste trabalho, as noções serão representadas graficamente entre barras obliquas. integração do contexto com as noções semânticas, a representação toma formas específicas na língua. Os Cenários 1a, 2a e 3a representam a fusão daquilo que estava dentro e fora dos colchetes nos Cenários 1,2 e 3.

Cenário 1a: Pedro-quebrador de brinquedo.

Cenário 2b: $O$ brinquedo quebrado por alguém.

Cenário 3c: $O$ ato de quebrar brinquedo por alguém.

A conformidade é resultado de uma avaliação, de uma medida ou estimativa, que leva em conta: (1) o ponto no qual se encontra uma dada representação (um objeto simbólico em construção) em uma situação específica de enunciação, e (2) um estado visado para um dado projeto de representação (um dado conteúdo predicativo ou de pensamento ${ }^{6}$ ).

A conformidade é alcançada como resultado da superação de eventuais desequilíbrios na trajetória da representação. Nessa trajetória, podem ter sido encontrados desde obstáculos à existência do processo ${ }^{7}$ (Pedro nem tentou quebrar alguma coisa) até obstáculos à predicação e à obtenção da transitividade ${ }^{8}$ (ou Pedro não conseguindo quebrar o brinquedo porque não se encontrou em Pedro propriedades para tanto ou o brinquedo impondo resistência a Pedro que por isso não consegue quebrá-lo). Obstáculos não superados sempre implicarão reorientação do projeto de representação que visa alcançar a fusão das noções com o contexto9.

${ }^{6}$ Trata-se de um objeto mais maleável do que as tradicionais categorias lógicas do pensamento.

Em 2006, participamos da correção das provas de um vestibular que tinha como tema o "Apagão aéreo". Naquele ano havia ocorrido a colisão de um jato Legacy com um Boeing da Gol e um dos textos de apoio retratava o acidente. Chamou nossa atenção o número expressivo de redações que referia a não colisão entre as duas aeronaves. Retomamos nossa experiência nesta nota porque ela corrobora a nossa argumentação.

8 O conceito de "transitividade" da tradição gramatical não é adequado para o tipo de processo em questão, porque refere apenas processos acabados e nomes construídos em trajetórias sempre adequadas, o que nem sempré o caso. Preferimos o conceito de causalidade para explicar trajetórias nem sempre bem-sucedidas de construção de predicação. Temos um jogo de forças entre a unidade e o contexto. Essas forças se deslocam em diferentes direções,
esboçando diferentes trajetórias de determinação de sentido. 
A representação, nesse caso, sendo situada em relação a uma situação particular de enunciação, toma formas específicas que trazem as marcas desse processo de realinhamento de trajetória. Como não é nosso propósito avançar na exposição desse tipo de processo, recomendamos a leitura de Rezende (2003). A autora produziu vários experimentos que dão visibilidade à articulação da reorientação nocional com a especificidade da organização léxico-gramatical. Aqui, voltemos a questionar o porquê de teorizar apenas as configurações previsíveis entre forma e conteúdo.

Quão previsíveis são as trajetórias pelas quais as noções semânticas tomam forma na língua? Podem ser previstas de um elenco (catálogo) de valores em termos de um "valor primeiro", outro "secundário", e assim por diante? Não haveria, nesse caso, tantas categorias quanto fossem os valores? Algumas categorias são mais "representativas" do que outras? Se as categorias são em número limitado, os valores estão sendo de fato apreendidos na sua especificidade? Nesse caso, quem e por que define o elenco? A que se deve a valoração de seus representantes? São previstas dos contextos as trajetórias das representações? São admissíveis dos contextos quaisquer noções? Há cenários preferíveis das noções? Há noções privilegiadas dos cenários? Por certo, não temos a pretensão de esgotar essas questões aqui levantadas.

Entendemos que a supressão da variação contextual (empírico), alicerçada, fundamentalmente, pela hipótese da estabilidade do sentido, é uma solução simplista que se traduz pela ilusão de conformidade de Pedro quebrou o brinquedo com o contexto enunciativo qualquer que seja ele. Seu corolário é a definição de um valor (o significado) que não varia, quer dizer, um valor constante (ou inerente) de Pedro quebrou o brinquedo e que se sobrepõe a cenários enunciativos variáveis. Entretanto, não se pode ignorar sem consequências a variação enquanto fenômeno observável dos cenários enunciativos tais como aqueles explicitados nesta seção para o evento quebrar.
De um certo ponto de vista, que não é o nosso, já se confundiu "fazer ciência" com a busca por eliminar ou domesticar a variação. Ressalte-se que, do nosso ponto de vista, estamos tratando a questão dentro de uma problemática da variação (experiencial e linguística). Não só assumimos a variação em toda a sua complexidade e profundidade, mas também tiramos algumas consequências dessa opção. Acreditamos que a redefinição do objetivo da linguística, qual seja a articulação da linguagem com as línguas naturais (CULIOLI, 1990) foi a de maior repercussão.

A seção seguinte dedica-se ao cotejo da variação tal como é entendida nos meandros da TOPE. Ressaltamos, em particular, as contribuições da abordagem epistemológica da variação por Culioli (1990; 1999) aos estudos em semântica.

\section{Para além dos fenômenos linguísticos previsíveis: a variação radical}

A variação diz respeito aos modos de perceber e representar o mundo por sistemas transindividuais não homogêneos (a instabilidade experiencial é fundamental) que, em princípio, não dialogam, senão em razão do trabalho dos sujeitos para se entender (quadro psicológico) e para se fazer entender (quadro sociológico). A representação do espaço não homogêneo (nível experiencial ou cognitivo)

não está sujeita à necessidade de um ajustamento intersubjetivo, elas fogem às vicissitudes dos construtos culturais baseados numa origem enunciativa onde estão em jogo as representações do sujeito e a sua inserção espaço-temporal, podendo-se ter designações e asserções unívocas, precisamente porque se trata de idealidades (CULIOLI, 1990, p. 43, tradução nossa) ${ }^{10}$.

${ }^{10}$ Do original: Elle n'est pas soumise à la nécessite d'un ajustement inter-subjectif, qu'elle échappe aux vicissitudes des référ pas soun à à partir d'une origine énonciative où jouent les représpe aux du sujet et son insertion spatio-temporelle, on peut avoir des désignateurs et des assertions univoques, précisément parce qu'il s'agit d'idéalités. 
As operações constitutivas da atividade significante buscam dar conta desse objeto cindido que é a articulação do particular experiencial, que se organiza e reorganiza, sempre em transformação, mas ainda investido de alguma "estabilidade provisória"11 ou "estados de equilíbrio local de um sistema [de significados gerados por cada unidade lexical em diferentes planos enunciativos] que muda ao longo do tempo" (MANTIA, 2012, p. 27, tradução nossa) ${ }^{12}$, com mecanismos operatórios que sempre estimam algum grau de variação sobre os construtos (sentidos construídos) do trabalho dos sujeitos.

Do ponto de vista da tese da indeterminação da linguagem, tal como estamos propondo neste trabalho, como lidar com a variação radical (REZENDE, 2008; 2014) que atravessa tanto a forma quanto o sentido ${ }^{13}$ ? Responderemos a essa pergunta, propondo a articulação entre forma e sentido na esteira de Culioli $(1990 ; 1999 ; 2002)$.

Para tanto, precisamos colocar, de imediato: um esquema formal instanciado por três noções semânticas, por exemplo, </Pedro/, /quebrar/, /brinquedo/>; um conjunto de operações de base ou de fundamento (operações da linguagem) e um conjunto de coordenadas de uma situação enunciativa dada. Ato contínuo, colocada em funcionamento por um sujeito, a linguagem compreende um conjunto de mecanismos que, de um lado, incidindo sobre um esquema formal, "prolifera sobre si próprio e explode em inúmeras significações” (REZENDE, 2000, p. 95) e, de outro lado, incidindo sobre a relação do esquema com a situação enunciativa, recorta a significação em efeitos semânticos.

${ }^{11} \mathrm{~A}$ atividade de linguagem, enquanto produto da atividade significante (DUCARD, 2009), articula uma memória ou uma projeção de significação (um horizonte de significação), por isso, provisória com quadros enunciativos variáveis. Portanto, o sentido não está dado por definição. Outrossim, é o construto da articulação de potencial significativo da unidade com suas diferentes contextualizações construto da articulação de potencial significativo da unidade com suas diferentes contextualizações (empírico)

Loriginal: stati di equilibrio locali di un sistema che muta nel tempo.

de que Saussure reduziu forma e sentido à oposição "significante" e "significado". Benveniste recobrou a diferença e a autonomia entre forma e sentido, mas não os articulou.
A linguagem, desse ponto de vista, deve ser entendida como a atividade de montagem e desmontagem de valores que são o resultado do ajustamento de configurações léxico-gramaticais (morfossintaxe e fonologia) a efeitos semânticos (obtidos por deformações sucessivas sobre domínios de significação) pretendidos para situações particulares de interação. Esses ajustamentos estão ligados ao funcionamento de um conjunto de operações de forma (hipersintaxe) que calibram enunciados e refinam o diálogo externo e a expressão dos sujeitos. Do ponto de vista da atividade de linguagem, como a metodologia lida com esse refinamento? E, por que nos fazem perguntas desse tipo?

Muito do que estamos retomando aqui já foi tratado, de um certo ponto de vista, como estilo, subjetivo, particular, desvio, doença, erro, e assim por diante. E, de um certo ponto de vista já se concluiu que tais fenômenos sejam pouco ou nada dignos da atenção da ciência ou de um certo tipo de ciência, que optou por dar atenção ao sistemático, objetivo, geral, regular, racional, acerto, e assim por diante. Por certo, somos indagados com frequência acerca da metodologia, quando assumimos que os fenômenos "residuais" ou os "desarranjos" já referidos na introdução e exemplificados na seção anterior (através de Pedro nem tentou quebrar alguma coisa, por exemplo) não podem fugir à alçada do linguista do ponto de vista da atividade de linguagem.

Será possível ter por objeto fenômenos que não se deixam classificar conforme os valores catalogados nas gramáticas e nos dicionários? Não vemos como responder a essa pergunta senão em termos das suas implicações teóricas e metodológicas.

Do ponto de vista teórico, temos de abandonar modelos classificatórios (fixos, estáticos, fechados) em favor de um modelo operatório (flexível, dinâmico, aberto). Do ponto de vista metodológico, temos de redefinir os observáveis. Essa mudança de perspectiva teórico-metodológica requer algum detalhamento. 
Primeiro, a linguagem desconhece os limites estabelecidos pela ciência (ou por um certo tipo de ciência) entre o que é variável e o que é invariável - os famigerados níveis de análise estratificados em fonético-fonológico, morfológico e sintático, que, na prática, operam a compartimentalização das formas da língua. Do ponto de vista da atividade de linguagem, tal como a entendemos, enquanto trabalho de construção de representação, referenciação e regulação (CULIOLI, 1990), a variação (interlínguas, intralínguas, intersujeitos, intrassujeitos) está na base da atividade de linguagem, em particular, e da atividade simbólica, em geral.

Segundo, o raciocínio metodológico fundamentado por categorias previsíveis e definidas pela ciência tende a excluir da observação todos aqueles fenômenos que não se encontram adequados. 0 raciocínio "científico" funciona do seguinte modo: Se $\boldsymbol{x}$ tem a forma de $\boldsymbol{y}$ e a função de $\mathbf{z}$, $\operatorname{logo}, \boldsymbol{x}$ é $\boldsymbol{w}^{14}$. Serão fenômenos observáveis desse tipo de ciência aqueles que estiverem adequados a essa formulação. Talvez não levante suspeição que o raciocínio científico esteja determinando o modo como são conhecidos os fenômenos. Talvez seja essa uma das constatações mais relevantes deste artigo.

Para certos fins, a categorização é um mecanismo bastante adequado a lidar com a variação. No entanto, o problema da variação é insolúvel do ponto de vista classificatório. Diante disso, nossa decisão é a de ir além, mas por um caminho diferente. Para tanto, coloquemos de um modo um pouco diferente a pergunta que nos fazem sobre a metodologia. Como controlar as inúmeras significações que proliferam a cada movimento de linguagem?

${ }^{14}$ Nessa formulação, $\boldsymbol{x}$ é um fenômeno qualquer (não-conhecido?), $\boldsymbol{y}$ é uma categoria conhecida (sua forma), assim como $\boldsymbol{z}$ (sua função) e $\boldsymbol{w}$ (como tendo a forma de $\boldsymbol{y}$ e a função de $\boldsymbol{z}$ ). Com efeito, obtém-se é urevisão racional segundo a qual: se $\boldsymbol{a}$, então, $\boldsymbol{b}$. Considere-se a unidade dar. Desse ponto de vista, um verbo, porque exibe uma dada morfologia (que se opõe àquela dos nomes) e um predicador, porque, na proposição, ocupa o lugar do predicado. Pois, bem. Se Pedro deu um livro à Maria, subsiste a esse raciocínio, o que dizer de Pedro deu uma olhada nos livros? Essa ocor
A paráfrase funciona como mecanismo de forma que fundamenta a equivalência dos enunciados. A paráfrase já foi entendida de três modos, pelo menos: (a) como a equivalência sintática ou estrutural ou formal entre frases ou sentenças (perspectiva lógica); (b) como a identidade semântica entre frases ou sentenças (perspectiva gramatical); e (c) como a reformulação do conteúdo (perspectiva retórica ou estilística) (FUCHS, 1985). Trataremos a atividade parafrástica ou o trabalho de parafrasagem como uma atividade de reformulação que coloca uma sequência em relação com muitas outras.

Sempre partimos de um contexto explícito, de um enunciado dado, por exemplo. Esse enunciado, se tem algum valor, só o apreendemos na medida em que o relacionamos a outros enunciados. Outros enunciados quaisquer? Não! Outros enunciados que sejam a tradução (interpretação) do meu enunciado de partida. Ao se movimentar um valor semântico de um lugar para outro no tempo-espaço e de um sujeito a outro, pode-se observar o papel das unidades morfolexicais na constituição da construção linguística. De um ponto de vista operatório, a continuidade e a descontinuidade vão se observar sempre e somente na passagem de um estado de língua a outro (CULIOLI, 2002).

Do ponto de vista metodológico, não reproduzimos os fenômenos. Porque esses são sempre únicos. Qualquer tentativa de reproduzi-los configura uma produção outra. Tomar essa produção segunda pela produção primeira não é sem consequência para o trabalho teórico. Por isso, em nosso trabalho, simulamos a produção e o reconhecimento de fenômenos de observação (CULIOLI, 1999, p. 53) num processo teoricamente controlado, e, depois, nós os aproximamos de outros fenômenos com os quais guardam alguma semelhança.

Diante de um conjunto de enunciados derivados de um esquema formal comum, observamos o processo pelo qual podem ser tomados como equivalentes ou pelo qual se excluem quando se faz variar as coordenadas 
de tempo-espaço e subjetivas. A parafrasagem e a desambiguização são os dois mecanismos de linguagem que temos para conduzir as observações. Estamos sempre aprendendo a formalizar (nos apropriando) as operações da linguagem através de diferentes configurações de unidades morfolexicais. É o que faremos neste trabalho.

Conforme anunciamos na introdução, tomamos a ambivalência do nome cachorro enquanto nome de propriedade (ser cachorro) e enquanto nome de indivíduos (um cachorro, outro cachorro, e assim por diante) como objeto de observação. Na seção seguinte relacionaremos essa ambivalência aos marcadores de operações de quantificação e qualificação no processo da determinação nominal.

\section{A determinação nominal: um movimento do formal ao empírico}

Construímos alguns fenômenos que simulam o diálogo, digamos, de um adulto com uma criança, para que não fiquem sem nomes nossos personagens. Estamos cientes da possibilidade da discordância do leitor quanto às construções ou quanto ao contexto no qual estão imersas ${ }^{15}$. Todavia, a discordância (variação) é o fundamento dos fenômenos que queremos observar. De fato, o que queremos explicitar é uma operação da linguagem: a determinação. 0 diálogo é o seguinte:

$\mathrm{O}$ adulto passeia pela rua com a criança.

(C1) Criança: - Um cachorro, mamãe.

(A1) Adulto: - Sim.

${ }^{15} \mathrm{O}$ diálogo foi apresentado a uma plateia de linguística em um evento científico. Na ocasião, os termos
do diálogo foram aceitos como adequados da situação que pretende ilustrar. Contudo, é de nossa ro diálogo foram aceitos como adequados
Mais adiante, outro cão aparece.

(C2) Criança: - O cachorro, mamãe.

$\mathrm{O}$ adulto faz uma advertência.

(A2) Adulto: -É outro cachorro

(C3) Criança: - Ele não é o cachorro, mamãe? - É outro? Não é o cachorro?

Recordemos de que, em linguística, o termo "determinação" está geralmente vinculado ao estudo da incidência de artigos definidos e indefinidos no grupo nominal e à identificação do tipo de referência (genérica ou específica) de uma sequência (CULIOLI, 1999, p. 37). Entretanto, o que aqui estamos propondo é o estudo da determinação em termos de um conjunto de operações elementares, tais como a extração, a flechagem, a quantificação e a qualificação (CULIOLI, 1990; 1999; 2002; REZENDE, 2000), cujos marcadores são constitutivos dos enunciados.

Em (C1), temos uma ocorrência da noção /ser cachorro/ que é introduzida no espaço enunciativo através da operação de extração, cujo marcador é um. A construção da existência simbólica da ocorrência é necessária para que se possa estabilizá-la do ponto de vista intersubjetivo. Em (A2), Sim é o marcador da estabilidade construída, porquanto valida a relação predicativa que projeta a existência de cachorro (C1), parafraseável por Eis um cachorro, mamãe.

A construção da existência enunciativa da ocorrência não é algo trivial. Ela implica que, primeiro, fragmente-se uma qualidade indivisível, que é a noção/ser cachorro, para que, segundo, possa ser extraída uma qualidade fragmentada que será individualizada em uma ocorrência e localizada no tempo-espaço de um sistema situacional. Chamaremos de ocorrência da noção a porção que lhe é extraída. A singularização de uma ocorrência linguística da noção é o mínimo que se possa fazer para referi-la no espaço enunciativo. 
Em (C1) um é o marcador da passagem de uma ocorrência (0) <nenhuma ocorrência de CACHORRO> para uma ocorrência (1) <uma ocorrência localizada de CACHORRO> e mamãe é o marcador do espaço referencial em relação ao qual a ocorrência (1) poderá ser tomada como objeto de discurso dos sujeitos (enunciador e co-enunciador).

Só depois de construída a existência simbólica da noção, no tempoespaço em que se inscreve, é que poderão ser feitas distinções qualitativas e quantitativas ulteriores sobre ela. No diálogo que estamos observando entre o adulto e a criança, o objeto simbólico cachorro, cujo sentido (a existência simbólica) foi construído (C1) e estabilizado (A1) do ponto de vista intersubjetivo, poderia ser objeto de predicações ulteriores através, por exemplo, de uma flechagem ou reidentificação.

A flechagem implica, primeiro, que se tenha construído a delimitação de um objeto simbólico no tempo-espaço delimitado por um sistema situacional e, segundo, que esse objeto simbólico em construção tenha sido estabilizado do ponto de vista intersubjetivo. Só então, numa eventual retomada enunciativa, possam ser feitas distinções qualitativas sobre ele. Na retomada, é ratificada a estabilidade existencial da ocorrência pela reidentificação. Tal é o caso em: Eu vi um cachorro. O cachorro...

Esse último exemplo traz duas ocorrências da noção /ser cachorro/: a primeira tem sua existência enunciativa predicada em Eu vi um cachorro (Eis que existe um cachorro tal ...); a segunda resulta da reidentificação de duas ocorrências da noção: uma delas ( $O$ cachorro ...) está sendo construída por uma asserção atual e a outra (Eu vi um cachorro) é uma ocorrência já estabilizada do ponto de vista intersubjetivo. $O$ artigo $o$ de $O$ cachorro é marcador do processo de reidentificação que acabamos de descrever. A flechagem marca reidentificaçao quantitativa e qualitativa da noção. No entanto, as operações de quantificação e qualificação não se resumem ao raciocínio da flechagem.
As delimitações quantitativa e qualitativa resultam de um certo recorte que um evento enunciativo opera sobre uma noção (GILBERT, 1999, p. 1). Construída a ancoragem situacional da ocorrência, condição para a sua existência simbólica, constrói-se a sua estruturação subjetiva, através da avaliação de uma ocorrência em relação a um centro organizador construído sobre um conjunto de ocorrências reais e imaginárias da noção, sendo que todas elas devem se identificar com uma ocorrência exemplar: o tipo.

Vislumbra-se um amplo espectro de ocorrências que, avaliadas em relação ao tipo, sejam ocorrências idênticas, quase idênticas, menos comuns, ocorrências com propriedades bastante significativas, ocorrências sem propriedade significativa, e assim por diante (GROUSSIER, 2000, p. 166). O tipo se caracteriza pelo seguinte raciocínio: Será uma ocorrência X da noção /ser cachorro/toda aquela que tiver a propriedade de /ser cachorro/. Com efeito, através do tipo pretende-se diferenciar qualitativamente ocorrências umas em relação às outras. É esse raciocínio que vai nos permitir distinguir, por exemplo, ocorrências qualitativamente idênticas, porque identificadas com um tipo, mas quantitativamente distintas quanto ao seu modo de existir no tempo-espaço. Uma paráfrase possível para esse raciocínio é: Eu vi um cachorro ontem, vi outro cachorro hoje, talvez veja outro cachorro amanhã.

Voltemos ao nosso diálogo. Em (C2) temos uma segunda ocorrência da noção /ser cachorro/. A questão é saber:

(a) se se trata da mesma ocorrência construída e estabilizada em um outro tempo-espaço, mas pelos mesmos sujeitos que se encontram no sistema situacional atual em que a ocorrência atual se inscreve. Aquela ocorrência traria consigo uma memória de estabilidade enunciativa. No diálogo de que partimos, a construção da ocorrência atual implicaria a identificação tanto quantitativa (continuidade existencial) quanto qualitativa (identificação com um tipo) entre as 
ocorrências de (C1) e (C2). A prosódia marcaria essa opção através do ritmo rápido, da intensidade em outro e na segunda sílaba de cachorro e da entonação descendente no final do enunciado.

(b) se se trata de uma ocorrência quantitativamente distinta da noção /ser cachorro/, mas qualitativamente identificada com uma ocorrência típica da noção /ser cachorro/. A ocorrência atual não traria consigo uma memória de estabilidade enunciativa, pois, a experiência com ocorrências variadas da noção /ser cachorro/ que sustenta o raciocínio não teria sido construída em relação a um sistema situacional, mas em relação à experiência singular de um mesmo sujeito em diferentes tempos-espaços. Com efeito, temos extrações sucessivas de ocorrências qualitativamente identificadas que ficam na dependência de estabilização intersubjetiva. No diálogo de que partimos, a construção dessa ocorrência implicaria a identificação qualitativa (identificação com um tipo) e a diferenciação quantitativa (ausência de continuidade existencial) entre as ocorrências de (C1) e (C2). A prosódia marcaria essa opção através do ritmo lento, da intensidade em outro e da leve ascendência da entonação no final do enunciado.

Antes de concluir, vejam-se algumas inferências construídas com base nos quadros formalizados em (a) e (b), quais sejam:

(i) a considerar a unidade $o$ de (C2) e sua historicidade no português, podemos inferir que, em (C2), temos o que se passa em (a). A considerar que, subjacente às formas da língua, temos uma invariante de base sustentando o diálogo, devemos entender que o enunciado (A2) marcaria: ruptura com a invariante e a impossibilidade do diálogo entre os interlocutores, que não estariam regulando sob o mesmo ponto de vista. (ii) a considerar que a criança está em processo de aquisição das formas da língua, a considerar que temos uma invariante de base sustentando o diálogo e a considerar que a ocorrência (C2) de cachorro careceria de ser estabilizada do ponto de vista intersubjetivo, estaríamos diante do processo descrito em (b).

\section{Considerações finais}

Defendemos desde o início que os fundamentos da linguagem não estão no objeto e não estão nos sujeitos. Os fundamentos da linguagem estão na clivagem dessas duas dimensões do empírico. Mas, como acessar esse plano mais profundo?

Para tanto, propusemos a hipótese de que o empírico constitui um agenciamento de unidades morfolexicais que são, de um lado, vestígios de representações cognitivas e, de outro lado, marcadores de operações. Definimos uma invariante de base, que organiza as unidades morfolexicais na construção de um conteúdo de pensamento.

Simulamos uma situação enunciativa e, manuseando as unidades morfolexicais um, o e cachorro dos enunciados do diálogo de partida, segundo os pressupostos da Teoria das Operações Predicativas e Enunciativas, formalizamos o funcionamento dessas formas no processo de determinação nominal e construímos algumas inferências com base nos quadros formalizados.

Com efeito, esperamos ter contribuído para a compreensão de que, de um ponto de vista enunciativo, a identidade das formas linguísticas é o construto de uma prática. Dada a articulação, formalizada em (a) e (b), das operações de extração, flechagem, quantificação e qualificação com a variação espaço-temporal e subjetiva, inferimos em (i) e (ii) uma identidade aproximada das formas do nosso diálogo de partida. 


\section{Referências}

BACHELARD, G. Filosofia do novo espírito científico. Lisboa: Presença, 1972.

BENVENISTE, E. Problemas de linguística geral I. 5. ed. Campinas: Pontes, 2005.

COMPRA. In: Michaelis Dicionário Brasileiro da Língua Portuguesa. São Paulo: Melhoramentos, 2015. Disponível em: https://michaelis.uol.com.br/modernoportugues/busca/portugues-brasileiro/compra/. Acesso em: 25 set. 2018.

CULIOLI, A. Pour une linguistique de l'énonciation: opérations et représentations. Paris: Ophrys, 1990.

CULIOLI, A. Pour une linguistique de l'énonciation: domaine notionnel. Paris: Ophrys, 1999.

CULIOLI, A. Variations sur la linguistique. Paris: KlincKsieck, 2002.

DUCARD, D. O grafo do gesto mental na teoria enunciativa de A. Culioli. Letras de hoje, Porto Alegre, v. 44, n. 1, p. 64-71, 2009.

FRANCKEL, J-J. Introduction. Langue française, n. 133, p. 3-15, 2002. https://doi. org/10.3406/lfr.2002.1042

FUCHS, C. A paráfrase linguística - equivalência, sinonímia ou reformulação? Cadernos de Estudos Linguísticos, Campinas, n. 8, p. 129-134, 1985.

GADOTTI, M; FREIRE, P.; GUIMARÃES, S. Pedagogia: diálogo e conflito. 4. ed. São Paulo: Cortez, 1995.

GILBERT, E. SOME et la construction d'une occurrence. Cycnos, [S. l.], v. 16, n. 2, p. 1-17 1999.

GROUSSIER, M.-L. On Antoine Culioli's theory of enunciative operations. Lingua, v. 110 p.157-182, 2000. https://doi.org/10.1016/S0024-3841(99)00035-2

MANTIA, F. la. Che senso ha? Polisemia e attivitá di linguaggio. Milão: Mimesis, 2012.
REZENDE, L. M. Léxico e gramática: aproximação de problemas linguísticos com educacionais. 2000. 330f. Tese (Livre-docência) - Faculdade de Ciências e Letras, UNESP, Araraquara, 2000. p. 124-125.

REZENDE, L. M. Causalidade, propriedade diferencial e construção de domínios nocionais. Alfa, São José do Rio Preto, v. 47, n. 2, p. 21-39, 2003

REZENDE, L. M. Atividade epilinguística e o ensino de língua portuguesa. Revista do GEL, São José do Rio Preto, v. 5, n. 1, p. 95-108, 2008.

REZENDE, L. M. A representação como projeto: um estudo sobre a nominalização. XVI Congreso Internacional de la ALFAL. Alcalá, 2011. p. 1621-1630.

REZENDE, L. M. Variação e invariância na teoria das operações predicativas e enunciativas. In: PRIA, A. D.; MORALIS, E. G.; CARDOSO-CARVALHO, V. F.; DE CARVALHO, G. A. (orgs.). Linguagem e línguas: invariância e variação. Campinas: Pontes, 2014. p. 81-90. 